\title{
Harmonic Resonances due to a Grid-connected Wind Farm
}

\author{
Ruimin Zheng, Math H. J. Bollen, and Jin Zhong
}

\begin{abstract}
This paper studies the impact of a grid-connected wind farm on the harmonic resonances. The basic theory on the harmonic resonances is introduced as well as its consequences. The models of wind farm for resonance analysis are presented for both calculations and simulations. The resonance orders and amplifications of voltage distortion with different capacity of capacitor banks are studied under different operation modes. Several case studies with a $200 \mathrm{MW}$ wind farm have been carried out to illustrate the methods for harmonic resonance analysis.
\end{abstract}

Index Terms-Induction machines, power quality, power system distribution, power system harmonics, wind power generation.

\section{INTRODUCTION}

W IND power penetration in the electric power system has been increasing rapidly in past 20 years in many countries and the total capacity of installed wind farm worldwide is expected to be $160 \mathrm{GW}$ by the end of 2010 . Therefore, the integration of wind power into the power grid poses great challenges to the existing power system. The harmonic analysis is a vital part in addressing the power quality problems involved with wind power installations.

Harmonics have been produced in power systems, ever since the first AC generator went online more the 100 years ago [1]. The presence of any non-linear element in the power system results in harmonics. Non-linear elements include transformers, power-electronic components, non-linear load, and power-electronic converters. As a periodic waveform distortion, harmonics exceeding a certain level has negative effects on customer equipment as well as the network components in the form of amplification of harmonic levels, reduction in efficiency of network components, ageing the insulation of electrical plant equipments, malfunctioning of system devices, and so on [2].

There are two main harmonic problems related to gridconnected wind farms. One is harmonic emission, and another one is harmonic resonance. Both of them are discussed in [3], with available measurement results from a small-sized but modern wind farm. The impact of the fault level at the

This work was partly supported by Areva T\&D and the HKU Seed Funding Programme for Basic Research (no. 200911159128).

Ruimin Zheng and Jin Zhong are with the Department of Electrical and Electronic Engineering, the University of Hong Kong, HKSAR, China (emails: rmzheng@eee.hku.hk, jzhong@eee.hku.hk ).

M. H. J. Bollen is with Electric Power Engineering, Luleå University of Technology, 98731 Skellefteå, Sweden, and with STRI AB, 77180 Ludvika, Sweden (e-mail: math.bollen@ltu.se ). connection point of the wind farm on the resonance frequency has also been studied in [3]. In [4], the harmonic resonances associated with a large wind farm were analyzed with considering the capacitance of the capacitor banks and cables that are part of the wind farm.

In this paper, we will briefly introduce the basic theory of harmonic resonances. The modeling of wind farm for resonances analysis is discussed, in which the inductance from wind turbine generators and turbine transformers has been taken into account as well as the capacitance from capacitor banks and cables. The impacts of harmonic resonances are studied by calculating amplifications of harmonic voltage and harmonic current with both an analytical method and a simulation method. The power-system analysis software DIgSILENT PowerFactory 14.0 has been used here as the simulation tool. Case studies have been carried out on a gridconnected wind farm containing 100 wind turbines. The influence of different operational modes on the resonances has also been studied.

The paper is structured as follows. In Section II, the harmonic resonances are briefly introduced. The model of a wind farm is presented for harmonic resonance analysis in Section III. Section IV discusses the parallel resonance and series resonance involved with a wind farm. In Section V, case studies are shown with detailed results and discussion. Conclusions are summarized in Section VI.

\section{HARMONIC RESONANCES}

Normally, the most severe harmonics appears at the terminals of polluting elements and their amplitude reduces with the increase of distance from its source. However, the resonances due to the presence of capacitive equipments can lead to amplification of harmonic levels where the highest levels occur elsewhere in the system than close to the source of distortion. Two types of resonance should be studied in depth: parallel resonance and series resonance.

\section{A. Parallel resonance}

Parallel resonance is associated with high impededance at resonance frequency which results in increased voltage distortion and high harmonic currents [5]. It may occur when a harmonic current source connects to the electrical components which can be simplified to be a parallel combination of a capacitive component and an inductive component as shown in Fig. 1. 


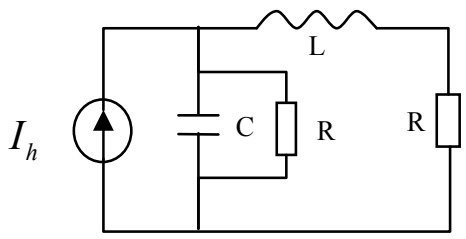

Fig. 1. Equivalent circuit for parallel resonance with considering resistances

A typical example is a medium-voltage substation where the capacitance is formed by a capacitor bank and the inductance by the transformer feeding in from a higher voltage level. When the resistances are neglected, the impedance seen by the harmonic source is as follows.

$$
\begin{aligned}
& Z(\omega)=\frac{j \omega L}{1-\omega^{2} L C} \\
& \omega=h \times 2 \pi f_{0}
\end{aligned}
$$

At the resonance frequency, $f_{r p}$, this impedance becomes infinite.

$$
f_{r p}=\frac{1}{2 \pi \sqrt{L C}}
$$

As the harmonic source is mainly a current source, high harmonic voltage occurs, and the harmonic current will be amplified to be an infinite value in the capacitive branch as shown in (4).

$\frac{I_{c a p}}{I_{h}}=\left|1-\frac{1}{1-h^{2} \omega^{2} L C}\right|$

However, the resistance is always presented in a real system. Hence, the impedance will not become infinite but will instead be limited by the resistance. Even though the resistances have slight influence on the resonance frequency, they are the main determining factor for the impedance and amplification close to the resonance frequency. The Fig. 2 shows impacts of transformer resistance and load resistance on the impedance at different harmonic orders, respectively. The curves are obtained with a system, in which a $70 \mathrm{kV}$ network with fault level of 1850 MVA is supplied by a $70 / 20 \mathrm{kV}$ transformer with fault level of 167 MVA. The total capacitance from capacitor banks and cables is $6.12 \mathrm{Mvar}$. The resistance of transformer is assumed to be linearly proportional to the frequency, while the load resistance is assumed to keep a constant value at any frequency.

The top figure shows the impact of the transformer resistance on the impedance seen by the distorting load. At the resonance frequency (harmonic order 5.1) the impedance increases linearly with the $\mathrm{X} / \mathrm{R}$ ratio. For integer harmonic orders, not at the resonance frequency, the impedance remains constant beyond a certain $\mathrm{X} / \mathrm{R}$ ratio.

The bottom figure shows the impact of the amount of resistive load; increasing amount of resistive load reduces the harmonic impedance with the impact being biggest at the resonance frequency.

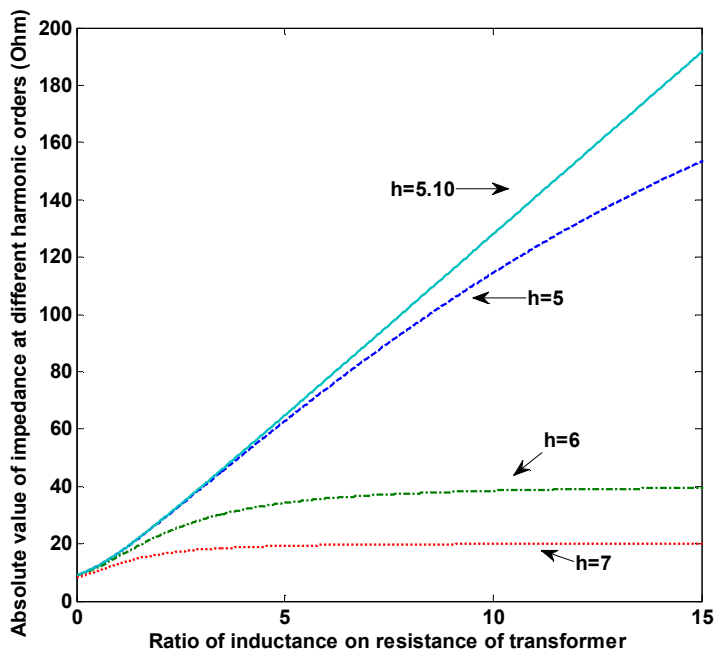

(a)

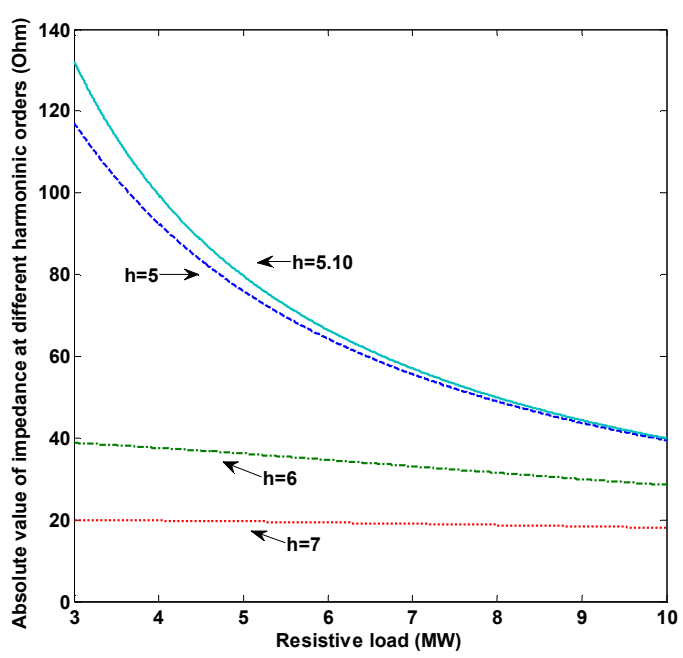

(b)

Fig. 2. Magnitude of impedances at different harmonic orders versus resistance from transformer and load.

\section{B. Series resonance}

Series resonance leads to low impedance at the resonance frequency which results in high current and a high voltage distortion even at locations where there is no or little harmonic emission [5]. It occurs when the local capacitance is in resonance with that connects the local bus to a remote bus with a high harmonic voltage. An equivalent circuit for series resonance is shown as in Fig. 3.

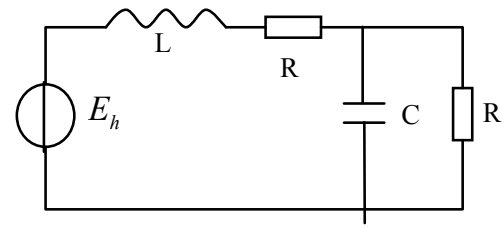

Fig. 3. Equivalent circuit for series resonance with considering resistances

When the resistances are neglected, the voltage $U_{h}$ at local bus can be calculated from the voltage $E_{h}$ at the remote bus by using (5). 


$$
U_{h}=\frac{1}{1-h^{2} \omega^{2} L C} E_{h}
$$

At the resonance frequency, $f_{r p}$, this voltage becomes infinite.

$$
f_{r s}=\frac{1}{2 \pi \sqrt{L C}}
$$

Where $C$ is the total capacitance connected to the local bus, $L$ is the inductance between local bus and remote bus, $h$ is the harmonic order.

Similarly, when the resistances are taken into account, the resonance order will not change noticeably, but the amplification of the voltage distortion will become a finite value. The influences of transformer resistance and load resistance on the amplification of voltage distortion are shown in the Fig. 4.

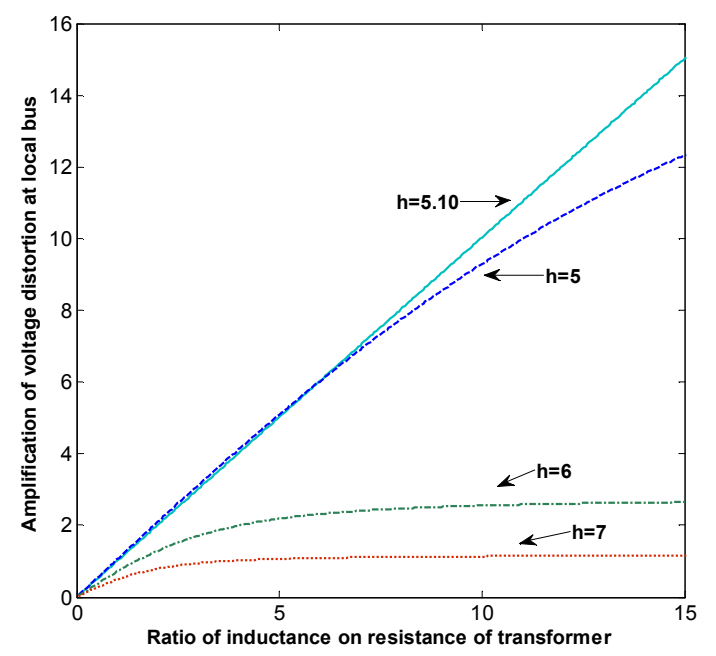

(a)

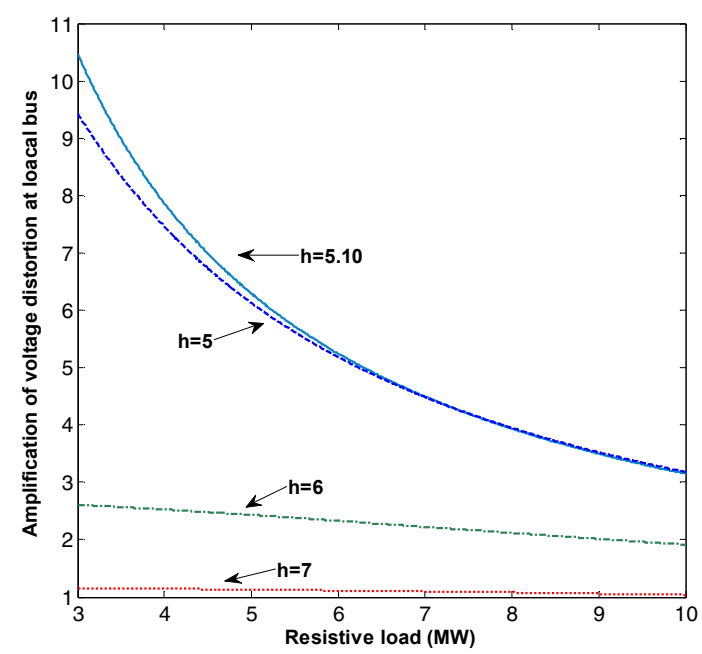

(b)

Fig. 4. Amplification of voltage distortion at different harmonic orders versus resistance from transformer and load.

The impact of transformer $\mathrm{X} / \mathrm{R}$ ratio and the amount of resistive load connected to the local bus is very similar to the impact on the impedance for a parallel resonance as shown in the previous section.

\section{MODELING WIND FARM FOR RESONANCE ANALYSIS}

When a wind farm is integrated into the power system, the step-up transformers and capacitor banks are added as well as the cables for collecting power, as shown in Fig. 5. These additional inductive and capacitive equipments will produce new harmonic resonance or change the resonance frequencies of existing harmonic resonances. To be able to calculate the resonance frequency and the amplitude of the impedance or amplification, it is important to accurately model the various power-system components.

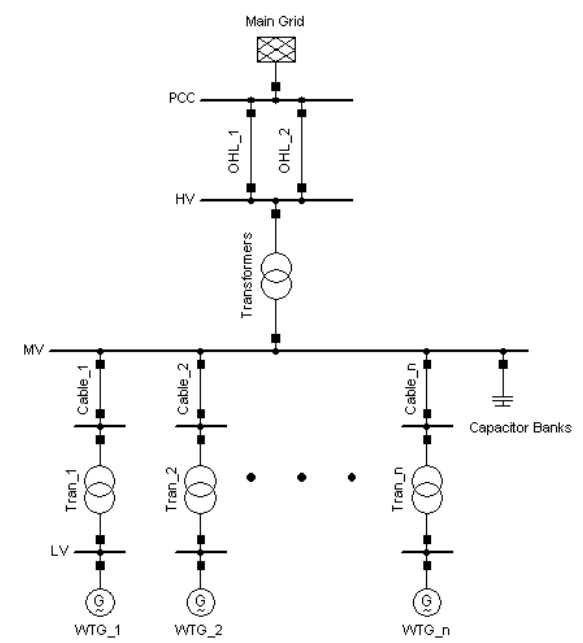

Fig. 5. Configuration of a grid-connected wind farm.

\section{A. Wind turbine generators}

The induction machine is used in most of the wind turbine generators as their electrical part. Based on the equivalent circuit of an induction machine for harmonic analysis, as has also been used in [4], a simplified equivalent circuit for harmonic resonance study is proposed as shown in Fig. 6. In the circuit diagram $R_{s}$ and $R_{r}$ are the stator resistance and rotor resistance, while $X_{s}$ and $X_{r}$ are the stator leakage reactance and rotor leakage reactance; $X_{m}$ refers to the magnetizing reactance.

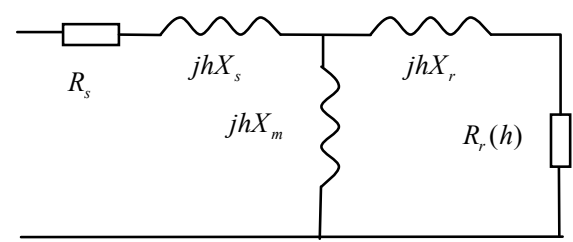

Fig. 6. Equivalent circuit of an induction machine for harmonic resonance analysis

\section{B. Collection system}

The Collecting system for a wind farm contains mediumvoltage (MV) cables, high-voltage (HV) overhead lines and transformers. The cables can be modeled as an equivalent capacitor, while the overhead lines and transformers can be modeled as a series combination of equivalent inductor and resistance. Both capacitance and inductance can be assumed frequency independent. The frequency dependency of the resistance should be considered in the calculations. Where possible this relation should be obtained from detailed calculations. This is however not always practical; further may 
the uncertainty in the estimated amount of resistive load dominate the uncertainty in the results. Therefore simplified expressions are often used, which we will discuss in the next section.

\section{Wind Farm}

Based on the equivalent circuits of the components in the wind farm, the grid-connected wind farm in Fig. 5 can be modeled as an equivalent circuit shown in Fig. 7, where the magnetizing reactance of induction machine is neglected.

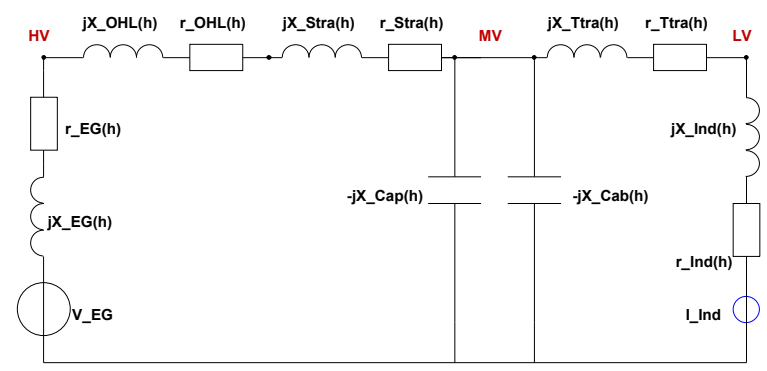

Fig. 7 Equivalent circuit for the grid-connected wind farm

As for the simulation, the resistance for different components can be modeled separately by associating a "frequency characteristic" to these quantities, according to their frequency dependent characteristics [6]. This characteristic is defined by a polynomial formula as (7).

$y\left(f_{h}\right)=(1-a)+a \bullet\left(\frac{f_{h}}{f_{1}}\right)^{b}$

The resulting value of the resistance is obtained by:

$\operatorname{Val}\left(f_{h}\right)=\operatorname{Val}\left(f_{1}\right) \times y\left(f_{h}\right)$

Therefore, the resistance of each component can be set to the values as shown in the Table 1, separately.

TABLE I

PARAMETERS OF RESISTANCE FREQUENCY CHARACTERISTICS FOR THE DIFFERENT COMPONENTS

\begin{tabular}{clc}
\hline Components & $\mathrm{a}$ & $\mathrm{b}$ \\
\hline WTGs & 1 & 0.5 \\
Main Grid & 1 & 0.5 \\
Transformers & 1 & 0.9 \\
Overhead lines & 1 & 0.3 \\
Cables & 1 & 0.5 \\
\hline
\end{tabular}

\section{HARMONIC RESONANCES DUE TO A WIND FARM}

Seen from the Fig. 6, the series resonance may occur at the HV substation, while the parallel resonance may occur at the MV substation.

\section{A. Series resonance}

The aim to study series resonance at the HV substation is to obtain the voltage distortion in the MV substation, which is caused by harmonics from voltage harmonic source on the HV substation at resonance frequency. This voltage distortion might damage the electrical equipment installed in the MV substation, such as capacitor banks. The high harmonic currents through the transformer may also result in overheating of the transformer or cause an unwanted trip of the transformer protection.
To identify the series resonance frequency is to find the minimum impedance value at the HV substation. According to the equivalent circuit in Fig. 7, the impedance at the HV bus is:

$$
\begin{gathered}
Z_{H V}(h)=Z_{E G}(h) / /\left(Z_{\text {OHL }}(h)+Z_{\text {Sub-Tra }}(h)+Z_{W F}(h) / / Z_{C}(h)\right) \\
=\frac{Z_{E G}(h) \times\left(Z_{O H L}(h)+Z_{\text {Sub-Tra }}(h)+Z_{W F}(h) / / Z_{C}(h)\right)}{Z_{E G}(h)+\left(Z_{\text {OHL }}(h)+Z_{\text {Sub-Tra }}(h)+Z_{W F}(h) / / Z_{C}(h)\right)} \\
Z_{C}(h)=-j\left(X_{C a b}(h) / / X_{C a p}(h)\right)
\end{gathered}
$$

So the series resonance occurs at the frequency where the impedance seen from the $\mathrm{HV}$ bus reaches its minimum absolute value. The amplification of voltage distortion at the MV substation can also be obtained by using (11) as follows.

$$
\left|\frac{U_{M V}}{U_{H V}}(h)\right|=\left|1-\frac{Z_{O H L}(h)+Z_{S u b-T r a}(h)}{Z_{O H L}(h)+Z_{S u b-T r a}(h)+Z_{C}(h) / / Z_{W F}(h)}\right|
$$

The resonance frequency can also be defined as the frequency at which the amplification is highest. This is not the same frequency as the one at which the impedance seen from the $\mathrm{HV}$ substation is lowest, but the two frequencies are close.

\section{B. Parallel resonance}

When the current sources connected at the MV bus emits a harmonic current close to parallel resonance frequency, a large voltage distortion will be produced on the MV substation, which leads to a large harmonic current through the capacitor banks.

As shown in the Fig. 7, the impedance seen from the MV bus is:

$$
\begin{gathered}
Z_{M V}(h)=\left(Z_{E G}(h)+Z_{O H L}(h)+Z_{\text {Sub-Tra }}(h)\right) / /\left(Z_{W F}(h) / / Z_{C}(h)\right) \\
=\frac{\left(Z_{E G}(h)+Z_{O H L}(h)+Z_{\text {Sub-Tra }}(h)\right) \times\left(Z_{W F}(h) / / Z_{C}(h)\right)}{Z_{E G}(h)+Z_{\text {OHL }}(h)+Z_{\text {Sub-Tra }}(h)+Z_{W F}(h) / / Z_{C}(h)} \text { (12) }
\end{gathered}
$$

The parallel resonance occurs at the frequency where the impedance seen from the MV bus reaches its maximum absolute value. And the amplification of the harmonic current flow in the capacitor banks can also be obtained by using (13) as follows.

$\left|\frac{I_{C a p}}{I_{M V}}(h)\right|=\left|\frac{\left(Z_{E G}(h)+Z_{\text {OHL }}(h)+Z_{\text {Sub-Tra }}(h)\right) \times \frac{Z_{W F}(h)}{Z_{W F}(h)+Z_{C}(h)}}{Z_{E G}(h)+Z_{O H L}(h)+Z_{\text {Sub-Tra }}(h)+Z_{W F}(h) / / Z_{C}(h)}\right|$

\section{CASE Studies}

Several cases have been studied to illustrate the harmonic resonance problems brought by a grid-connected wind farm. The wind farm used for the studies is based on the example presented in [4]: it consists of 100 wind turbines with rated power of $2 \mathrm{MW}$ and terminal voltage of $690 \mathrm{~V}$ each. 100 turbine transformers and underground cables of $34.5 \mathrm{kV}$ are used to connect the wind turbines to the MV substation. A total of 72 Mvar capacitor banks, which is switchable in steps of 12 Mvar, are also installed in the MV substation. The power from wind farm substation is transmitted to the main grid through two $115 / 34.5 \mathrm{kV}$ transformers and two parallel 115 $\mathrm{kV}$ overhead lines. 
The 100 wind turbines are assumed to be located in 10 rows and 10 columns, as shown in Fig. 8. The wind farm substation is in the center place with a vertical distance of 500 $\mathrm{m}$ to the centre of first row. In order to decrease the wake effect, the distance between two rows is $320 \mathrm{~m}$, while the distance between two columns is $640 \mathrm{~m}$. Therefore, the total length of the underground cables is about $45.9 \mathrm{~km}$, which accounts for a total capacitance equivalent to 4.29 Mvar.

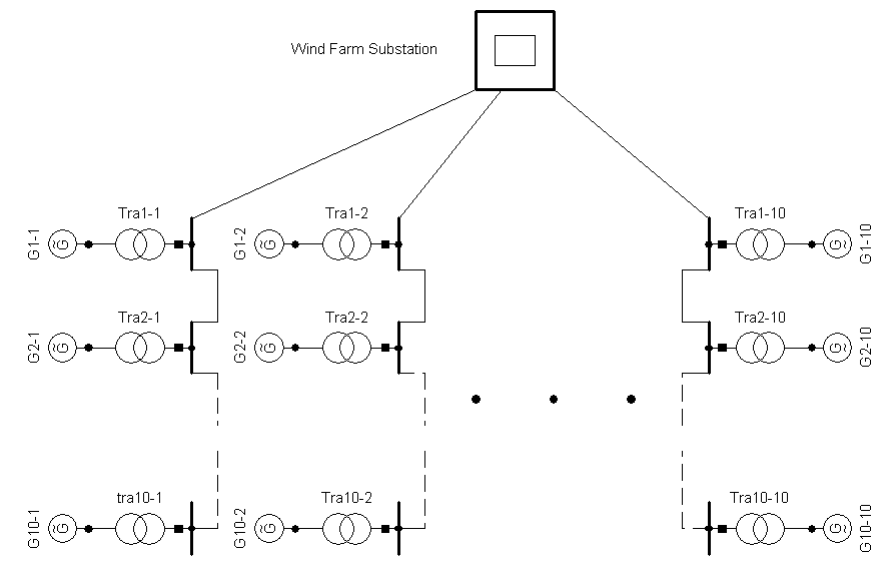

Fig. 8 Layout of the grid-connected wind farm

The resonance analyses have been carried out by both analytical calculation with MATLAB and simulation with PowerFactory. The calculation is base on the models proposed in Section IV, while the harmonic analysis tool of PowerFactory is used in the simulation. The connections between the 10 wind turbines in the first column have been modeled in detail to study the harmonic resonance at the point near to the wind turbines. The other 90 wind turbines and turbine transformers are merged into 9 combinations, in which 10 wind turbines and 10 turbine transformers are connected in parallel. The model built in PowerFactory is shown as in Fig. 9.

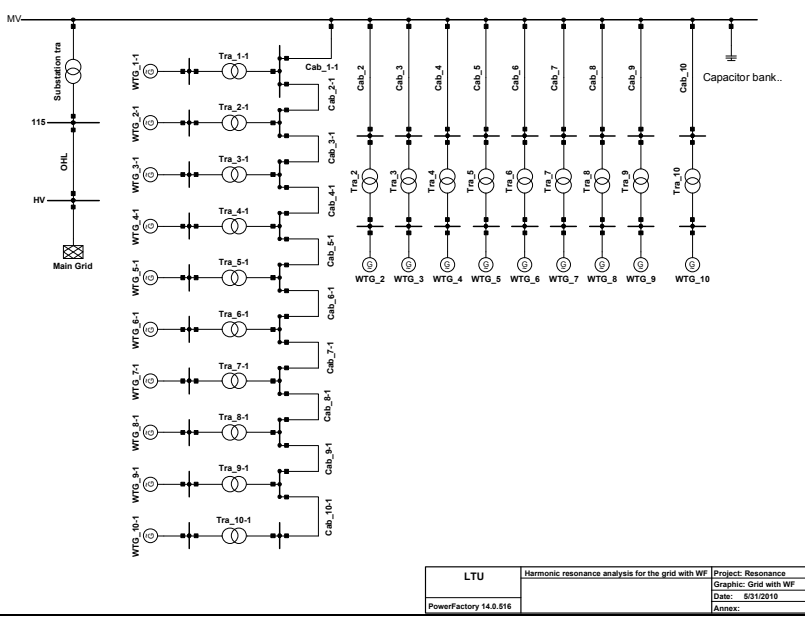

Fig. 9 Modeling of a grid-connected wind farm in PowerFactory

The resonance order can be obtained by processing the frequency sweep. The simulation results when none or all capacitor banks are connected ( 72 Mvar) are shown in the Fig. 10(a) and 10(b), where in both cases the upper curve is the impedance at the HV bus and the lower one is the impedance at the MV bus.

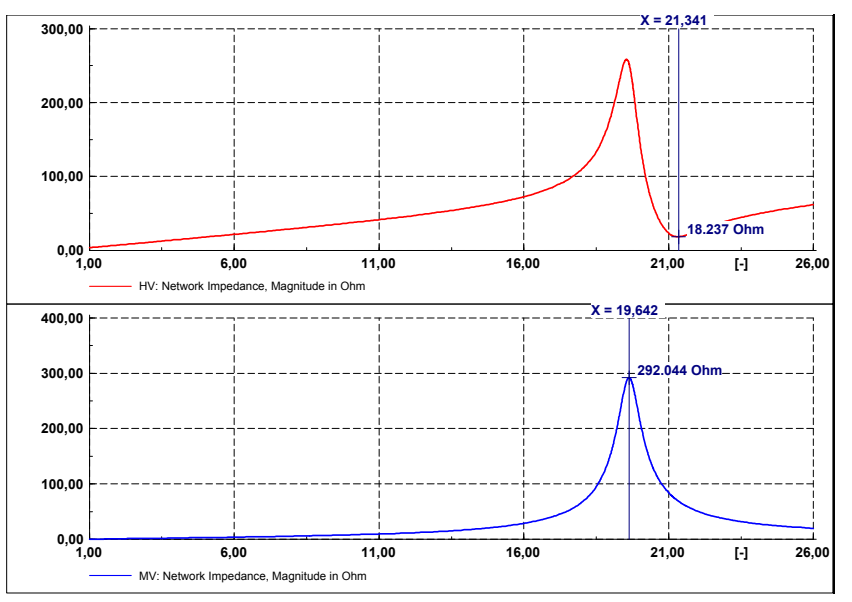

(a) $Q_{c a p}=0 M$ var

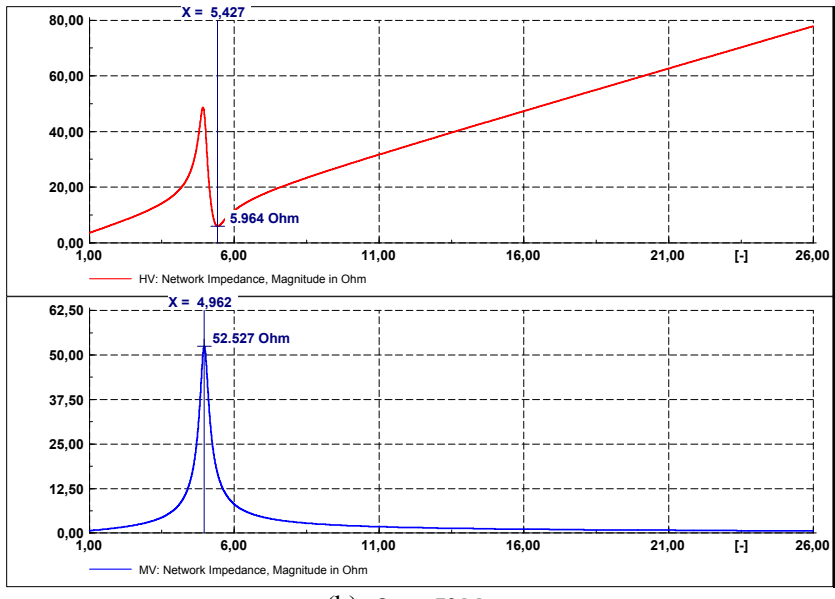

(b) $Q_{\text {cap }}=72 M$ var

Fig. 10 Results of frequency sweep at the HV bus and the MV bus

Without capacitors connected, resonances occur around harmonic order $20(1 \mathrm{kHz})$, whereas the resonance frequency goes down to below $300 \mathrm{~Hz}$ when all $72 \mathrm{MVA}$ of capacitor banks is connected. Seen from the MV bus only a series resonance is visible, which will cause an increased voltage distortion due to emission by the wind turbines. This is normally of minor concern, but it is worth checking in all cases. Seen from the HV bus both a series and a parallel resonance are visible; the concern is with the series resonance (the low impedance value), as explained in Section II.

The resonance orders for different amounts of capacitance connected are listed in the Table II. There is little difference between simulation results and calculations. The different treating methods for resistances of the electrical components do not affect the resonance order significantly, for the resistances are rather small compared to the reactance. The resonance frequencies vary a lot with different amounts of capacitance connected to the MV bus.

The parallel resonances at the high voltage side of the 10 turbine transformers in the first column have also been analyzed by simulation, when the capacity of capacitor banks is 72 Mvar. The results are shown in Table III, which indicate that the cable is not the main factor of impacting the harmonic resonances.

TABLE II

HARMONIC RESONANCE ORDERS WITH DIFFERENT AMOUNT OF CAPACITOR BANKS 


\begin{tabular}{ccccc}
\hline \multicolumn{1}{c}{$\begin{array}{c}\text { HVacitor } \\
\text { banks }\end{array}$} & Simulation & Calculation & Simulation & Calculation \\
\hline 0Mvar & 21.34 & 22.8 & 19.64 & 21.7 \\
12Mvar & 11.57 & 11.7 & 10.61 & 10.8 \\
24Mvar & 8.859 & 8.88 & 8.106 & 8.21 \\
36Mvar & 7.429 & 7.45 & 6.809 & 6.88 \\
48Mvar & 6.544 & 6.54 & 5.985 & 6.04 \\
60Mvar & 5.905 & 5.89 & 5.402 & 5.44 \\
72Mvar & 5.427 & 5.41 & 4.962 & 5 \\
\hline
\end{tabular}

TABLE III

HARMONIC RESONANCE ORDERS AT DIFFERENT LOCATION

\begin{tabular}{cc|cc}
\hline $\begin{array}{c}\text { Near to the } \\
\text { transformer }\end{array}$ & $\begin{array}{c}\text { Resonance } \\
\text { orders }\end{array}$ & $\begin{array}{c}\text { Near to the } \\
\text { transformer }\end{array}$ & $\begin{array}{c}\text { Resonance } \\
\text { orders }\end{array}$ \\
\hline $1-1$ & 4.958 & $6-1$ & 4.956 \\
$2-1$ & 4.957 & $7-1$ & 4.956 \\
$3-1$ & 4.957 & $8-1$ & 4.955 \\
$4-1$ & 4.957 & $9-1$ & 4.954 \\
$5-1$ & 4.956 & $10-1$ & 4.954 \\
\hline
\end{tabular}

The operation modes of overhead lines and substation transformers are changed to study their influences on the series resonance. When series resonance occurs, the voltage distortion might be amplified at the MV bus. The $5^{\text {th }}$ and $7^{\text {th }}$ harmonics are regarded as the dominant harmonics in most transmission system. These harmonics originate from domestic and commercial customers [5]. So the amplifications of voltage distortion with $5^{\text {th }}$ and $7^{\text {th }}$ harmonics are calculated as well as the resonance orders with different capacity of capacitor banks, based on the simulation results. The simulation results are shown in the Table IV to Table VI.

TABLE IV

HARMONIC RESONANCES UNDER FULL OPERATION

\begin{tabular}{ccccc}
\hline $\begin{array}{c}\text { Capacitor } \\
\text { banks }\end{array}$ & $\begin{array}{c}\text { Resonance } \\
\text { orders }\end{array}$ & \multicolumn{3}{c}{$\left|U_{M V}(h) / U_{H V}(h)\right|$} \\
\hline 0Mvar & 21.34 & 10.81 & 0.5727 & 0.6053 \\
12Mvar & 11.57 & 9.965 & 0.6671 & 0.8531 \\
24Mvar & 8.859 & 9.059 & 0.7968 & 0.5089 \\
36Mvar & 7.429 & 8.735 & 0.9353 & 2.943 \\
48Mvar & 6.544 & 8.246 & 0.6530 & 3.004 \\
60Mvar & 5.905 & 8.003 & 0.7015 & 1.227 \\
72Mvar & 5.427 & 7.747 & 1.795 & 0.7657 \\
\hline
\end{tabular}

TABLE V

HARMONIC RESONANCES WITH ONE OVERHEAD LINE

\begin{tabular}{ccccc}
\hline $\begin{array}{c}\text { Capacitor } \\
\text { banks }\end{array}$ & $\begin{array}{c}\text { Resonance } \\
\text { orders }\end{array}$ & \multicolumn{3}{c}{$\left|U_{M V}(h) / U_{H V}(h)\right|$} \\
& & Resonance order & 5 & 7 \\
\hline 0Mvar & 19.26 & 8.393 & 0.4597 & 0.4935 \\
12Mvar & 10.42 & 7.321 & 0.5599 & 0.7863 \\
24Mvar & 7.978 & 6.572 & 0.7134 & 0.9563 \\
36Mvar & 6.702 & 6.231 & 0.8985 & 3.110 \\
48Mvar & 5.902 & 5.847 & 0.3350 & 0.9355 \\
60Mvar & 5.329 & 5.633 & 2.134 & 0.5451 \\
72Mvar & 4.896 & 5.502 & 4.504 & 0.3842 \\
\hline
\end{tabular}

TABLE VI

HARMONIC RESONANCES WITH ONE SUBSTATION TRANSFORMER

\begin{tabular}{ccccc}
\hline $\begin{array}{c}\text { Capacitor } \\
\text { banks }\end{array}$ & $\begin{array}{c}\text { Resonance } \\
\text { orders }\end{array}$ & \multicolumn{3}{c}{$\left|U_{M V}(h) / U_{H V}(h)\right|$} \\
\hline OMvar & 19.67 & 7.617 & 0.4833 & 0.5170 \\
12Mvar & 10.65 & 6.806 & 0.5830 & 0.8017 \\
24Mvar & 8.136 & 6.378 & 0.7322 & 0.1247 \\
36Mvar & 6.846 & 5.994 & 0.9075 & 4.336 \\
\hline
\end{tabular}

\begin{tabular}{lllcl} 
48Mvar & 6.029 & 5.676 & 0.9257 & 1.1162 \\
60Mvar & 5.411 & 5.494 & 1.309 & 0.6267 \\
72Mvar & 5.004 & 5.686 & 5.377 & 0.4348 \\
\hline
\end{tabular}

In all three cases the amplification is highest at the resonance frequency. This could be a problem with high levels of interharmonics being presented in the transmission system or when a power-line communication signal has a frequency close to the resonance frequency. The amplification at the resonance frequency is more than a factor five in all cases.

A more general concern is the amplification at the fifth and seventh harmonic, because these frequencies are always presented in the transmission system. Here we see that the amplification varies strongly based on the operational state. With both lines and both transformers in operation, the seventh harmonic may be amplified up to three times when 36 or 48 Mvar of capacitance in connected. For 72 Mvar of capacitance, the fifth harmonic is amplified by a factor of 1.8 . When one line or one transformer is out of operation, the maximum amplification increases for both the 5 th and the 7 th harmonics.

\section{CONCLUSIONS}

Harmonic resonance analysis is a vital part in the planning and operation of grid-connected wind farms. The added capacitive components and inductive components might lead to harmonic resonances around $5^{\text {th }}$ and $7^{\text {th }}$ harmonics. This may results in high voltage distortion at the bus where the capacitor banks are installed. The resonance analyses with different capacity of capacitor banks and operation modes have been studied by calculation and simulation. The results indicate that the resistances have only a minor effect on resonance orders but significant effect on the amplification of voltage distortion. The amount of capacitor banks connected is the essential influencing factor for harmonic resonances. Harmonic filters are needed in certain operation scenarios, which will be an emphasis of the further research.

\section{ACKNOWLEDGMENT}

The authors gratefully acknowledge the contributions from E. O. A. Larsson, M. Lundmark, M. Wahlberg, Kai Yang, and S. K. Rönnberg.

\section{REFERENCES}

[1] C. Sankaran, Effects of harmonics on power systems - part 1, in EC\&M, [online]. http://ecmweb.com/mag/electric_effects_harmonics_power_2/.

[2] J. Arrillaga and N. R. Watson, Power System Harmonics, 2nd Edition, John Weily \& Sons, 2004.

[3] M.H.J. Bollen, L. Yao, S.K. Rönnberg, and M. Wahlberg. "Harmonic and Interharmonic Distortion due to a Windpark", in IEEE Power \& Energy Society General Meeting, 2010.

[4] J. Li, N. Samaan, and S. Williams, "Modeling of Large Wind Farm Systems for Dynamic and Harmonics Analysis", in IEEE/PEEE Transmission and Distribution Conference and Exposition, pp. 1-7, April 2008.

[5] M.H.J. Bollen and I.Y.H. Gu. Signal Processing of Power-Quality Disturbances. New York: IEEE Press, 2006.

[6] DIgSILENT GmbH. "DIgSILENT PowerFactory 14.0, Manual." 2008. 


\section{BIOGRAPHIES}

Ruimin Zheng received the B.Sc. degree from North China Electric Power University, China in 2005 and M.Sc. degree from Xian Jiaotong University, China in 2008. She is now a PhD student in the Department of Electrical and Electronic Engineering, the University of Hong Kong. Her main field of interest is renewable energy, wind power, and energy storage system.

Math Bollen (M'93-SM'96-F'05) received the M.Sc. and Ph.D. degrees from Eindhoven University of Technology, Eindhoven, The Netherlands, in 1985 and 1989, respectively. He is professor in electric power engineering at Luleå University of Technology, Skellefteå, Sweden, senior specialist at STRI AB, Gothenburg, Sweden and technical expect at the Energy Markets Inspectorate, Eskilstuna, Sweden. . He has among others been a lecturer at the University of Manchester Institute of Science and Technology (UMIST), Manchester, U.K., and professor in electric power systems at Chalmers University of Technology, Gothenburg, Sweden. He has published a number of fundamental papers on voltage dip analysis and two textbooks on power quality, "understanding power quality problems" and "signal processing of power quality disturbances".

Jin Zhong (M'04) received the B.Sc. degree from Tsinghua University, Beijing, China, in 1995, the M.Sc. degree from China Electric Power Research Institute, Beijing, in 1998, and the $\mathrm{PhD}$ degree from Charmers University of Technology, Gothenburg, Sweden, in 2003. At present, she is an Assistant Professor in the Department of Electrical and Electronic Engineering of the University of Hong Kong. Her areas of interest are electricity sector deregulation, ancillary service pricing, and distributed generation. 